IZA DP No. 10244

On Measuring Uncertainty:

Snakes and Ladders

P.N. (Raja) Junankar

September 2016 


\title{
On Measuring Uncertainty: Snakes and Ladders
}

\author{
P.N. (Raja) Junankar \\ IRRC, University of New South Wales, \\ University of Western Sydney and IZA
}
Discussion Paper No. 10244
September 2016

\author{
IZA \\ P.O. Box 7240 \\ 53072 Bonn \\ Germany \\ Phone: +49-228-3894-0 \\ Fax: +49-228-3894-180 \\ E-mail: iza@iza.org
}

\begin{abstract}
Any opinions expressed here are those of the author(s) and not those of IZA. Research published in this series may include views on policy, but the institute itself takes no institutional policy positions. The IZA research network is committed to the IZA Guiding Principles of Research Integrity.

The Institute for the Study of Labor (IZA) in Bonn is a local and virtual international research center and a place of communication between science, politics and business. IZA is an independent nonprofit organization supported by Deutsche Post Foundation. The center is associated with the University of Bonn and offers a stimulating research environment through its international network, workshops and conferences, data service, project support, research visits and doctoral program. IZA engages in (i) original and internationally competitive research in all fields of labor economics, (ii) development of policy concepts, and (iii) dissemination of research results and concepts to the interested public.
\end{abstract}

IZA Discussion Papers often represent preliminary work and are circulated to encourage discussion. Citation of such a paper should account for its provisional character. A revised version may be available directly from the author. 
IZA Discussion Paper No. 10244

September 2016

\section{ABSTRACT}

\section{On Measuring Uncertainty: Snakes and Ladders*}

The Global Crisis demonstrated to the world that Ratings Agencies had misled the public about the stability of financial institutions. The Finance literature had decided that it was impossible to have bubbles in financial markets and any surge in the stock market would be self-correcting. Recent papers have discussed the role of "uncertainty" and its measurement in influencing economic decisions. They attempt to measure uncertainty by indexes of volatility of the stock market, GDP, forecaster disagreement, mentions of uncertainty in news media, and the dispersion of productivity shocks to firms. Underlying their measures of uncertainty is the hypothesis that an increase in uncertainty leads to lower consumption by households and lower investment by firms, and hence leads to lower aggregate investment and growth. This paper argues that although risk can be measured, uncertainty cannot be measured. Even though risk can be measured, a simple symmetric measure (variance or standard deviation) is inappropriate because agents are loss averse and treat gains differently from losses. Although, it is clear that an increase in uncertainty worsens economic conditions, in this paper I shall also argue that this attempt at "measuring" risk or (fundamental) uncertainty is flawed.

JEL Classification: E12, E22, G01, G11

Keywords: $\quad$ uncertainty, risk, Keynes, variance measures, loss aversion, investment

Corresponding author:

P.N. (Raja) Junankar

Industrial Relations Research Centre

Australian School of Business

University of New South Wales

Sydney NSW 2052

Australia

E-mail: raja.junankar@uws.edu.au

\footnotetext{
* I am grateful to Geoff Harcourt, Peter Kriesler, Alec Chrystal and Mono Chatterji for helpful comments on an earlier version of this paper. They are, obviously, not responsible for errors or views expressed in this paper.
} 


\title{
On Measuring Uncertainty: Snakes and Ladders ${ }^{1}$
}

\section{P.N. (Raja) Junankar}

\begin{abstract}
The message is that there are known knowns. There are things we know that we know.

There are known unknowns. That is to say there are things that we now know we don't know.

But there are also unknown unknowns. There are things we don't know we don't know.
\end{abstract}

$$
\text { Donald Rumsfeld, (February 2002) }
$$

\section{Introduction}

The Global Financial Crisis (GFC) (or the Global Crisis) demonstrated to the world that leading financial institutions, which had been rated as triple A, were insolvent and crashed. Even though we had high powered mathematical economists and financial experts advising ratings agencies and finance houses about risk and uncertainty they all got it wrong! The Finance literature had decided that it was impossible to have bubbles in financial markets and any surge in the stock market would be self-correcting. In the light of this it is interesting to see that in recent work, Bloom (2014), Baker et al. (2015) and Moore (2016) have discussed the role of "uncertainty" and its measurement in influencing economic decisions. They attempt to measure uncertainty by indexes of volatility of the stock market, GDP, forecaster disagreement, mentions of uncertainty in news media, and the dispersion of productivity shocks to firms. Armed with these measures of uncertainty, economists should be able to forecast the next great recession, or at least that is the aim. Moore (2016) has created a composite index of the above mentioned components using Australian data. Underlying their measures of uncertainty is the hypothesis that an increase in uncertainty leads to lower consumption by households and lower investment by firms, and hence leads to lower aggregate investment and growth. Even though risk can be measured, a simple symmetric measure (variance or standard deviation) is inappropriate because agents are loss averse and treat gains differently from losses. Although, it is clear that an increase in uncertainty worsens economic conditions, in this paper I shall argue that attempts at "measuring” risk or (fundamental) uncertainty is flawed.

\footnotetext{
${ }^{1}$ Snakes and Ladders is an old children's board game: to win you have to reach the end of the board but on the way face hazards (the mouth of a snake which takes you down several squares) and bounties (the bottom of a ladder that takes you several squares higher towards the end). Not surprisingly, players prefer ladders to snakes!
} 


\section{Some Background}

Prior to the Global Crisis economists had argued that financial bubbles were impossible and the financial institutions had sophisticated methods of dealing with risk and uncertainty. However, after the GFC there has been much soul searching about how such a financial collapse could have occurred. The British set up the Turner Review (2009) and the US Government set up the Financial Crisis Inquiry Commission that reported in 2011. These reports clearly show that the deregulation of the financial sector let loose a whole range of new financial products: derivatives, Credit Default Swaps (CDSs), and Collateralised Debt Obligations (CDOs). On top of that the credit rating agencies, e.g. Moody's, were giving triple A ratings to some of these financial products without a real understanding of how these products had been created. As the Financial Crisis Inquiry Commission Report shows that this plethora of new financial instruments that were not regulated was one of the reasons for the Global Crisis. See the quotes below:

"We conclude the failures of credit rating agencies were essential cogs in the wheel of financial destruction.” Financial Crisis Inquiry Commission Report (2011) Conclusions (p.xxv).

"Financial institutions and credit rating agencies embraced mathematical models as reliable predictors of risks, replacing judgment in too many instances. Too often, risk management became risk justification.” (Financial Crisis Inquiry Commission Report (2011), Conclusions p. xix).

The Turner Review (2009) was similarly critical of the financial system prior to the GFC. It argued that there were fundamental flaws in the concept of Value-at-Risk (VAR) which was based on past patterns of price movements.

"There are, however, fundamental questions about the validity of VAR as a measure of risk (see Section 1.4 (ii) below). And the use of VAR measures based on relatively short periods of historical observation (e.g. 12 months) introduced dangerous procyclicality into the assessment of trading book risk ..." (Turner 2009, p. 22)2

Both the Turner Review and the Financial Crisis Inquiry were critical of the sophisticated mathematical models that were being used to evaluate risks.

\footnotetext{
2 See Appendix.
} 


\section{Bloom on Uncertainty}

The main issues studied by Bloom (2014) are firstly, "macro and micro uncertainty appear to rise sharply in recessions and fall in booms" (p. 153). Secondly, whether uncertainty varies with the business cycle, and thirdly, whether uncertainty affects economic behaviour negatively. He "refer[s] to a single concept of uncertainty, but it will typically be a stand-in for a mixture of risk and uncertainty" (p. 154).

His measure of uncertainty looks at the volatility of the stock market or GDP by plotting a VIX index of volatility of the Standard and Poor's 500 stock market index. ${ }^{3}$ A graph then shows that during recessions (NBER dated recessions) the VIX index rises. Other indexes he considers are disagreement amongst professional forecasters, again using a standard deviation measure. He finds that this index is higher in recessions. Similarly, an index based on the frequency of newspaper articles about economic uncertainty is used to suggest that it increases during recessions. On micro uncertainty, he looks at the dispersion of industrial production growth and of dispersion of sales growth of plants in US manufacturing. Using a variance measure he finds that the variance increases during recessions. Note that standard deviation or variance measures used as an index of uncertainty treat observations below and above the mean symmetrically, that is, if observations are above the average they are equally bad as if they are below the average.

The next section of his paper then provides an interesting account of why uncertainty matters in theory. The summary of the empirical evidence leads Bloom to argue that although there is evidence that uncertainty is harmful for short-run growth, the evidence that it has a harmful impact on long-run growth is not proven. Bloom argues (correctly) that increased uncertainty has led to the large impact of the Global Recession (Great Recession) on GDP and also the prolongation of the crisis by delaying investment by firms.

\section{Moore (2016) Measuring Economic Uncertainty}

Although conscious of the distinction between risk and uncertainty he refers to "a single concept of uncertainty that blends both in this paper" (Moore, 2016, p. 1). The paper provides a weighted average index of "uncertainty" using Australian data that combines "newspaperbased measures of uncertainty,...4; finance-based measures, such as stock market volatility; and measures of disagreement among forecasters ...” (p. 1). Two measures of stock market volatility are used. The first one is realised volatility, measured by the monthly average of the daily absolute percentage change in the All Ordinaries index. The second measure is a forward looking one. This measure of stock market volatility is based on call and put options of the ASX 200 index. It represents the expected one-month-ahead volatility in the ASX 200.

The weighted average index of uncertainty is then scaled to have a mean of 100 points and a standard deviation of 30 points. Apparently, this is to mimic the US uncertainty index from Baker et al. (2015). However, it seems odd to assume that the US and Australia markets are so highly correlated.

Interestingly, he finds that the "distribution of changes in the index is positively skewed,...The distribution is significantly different from the normal distribution." (emphasis added, p. 14).

\footnotetext{
3 See Brenner and Gali (1993) for a discussion of the VIX index.

${ }^{4}$ Moore standardised this newspaper based measure of uncertainty, to have a standard normal distribution with mean zero and unit standard deviation.
} 
Using a VAR model on monthly Australian data, the author then finds that a shock to the uncertainty index leads to lower employment growth and a small (insignificant) impact on retail sales. This evidence is provided graphically but the econometric results of the VAR model are not presented in the paper. However, it is assumed that the impact of these shocks is symmetric: an increase in uncertainty lowers employment growth and a decrease in uncertainty increases employment growth. In the next section I argue that the impact of uncertainty on economic variables (consumption, investment, growth) is asymmetric.

\section{Keynes on Uncertainty}

Knight (1921) in a classic book distinguished between risk (an objective probability distribution with known probabilities) and uncertainty (an unknown probability distribution). I shall refer to uncertainty in the Keynesian sense as "fundamental uncertainty" or as O'Donnell (2013) calls "irreducible uncertainty". ${ }^{5}$ Keynes in his General Theory emphasised the role uncertainty plays in determining investment by firms. For Keynes, there are fluctuations in the level of income (GDP) caused by changes in Investment that are sudden and uncertain (unexpected). The equilibrium level of GDP is based on given "long-term expectations"6. But these long-term expectations can shift suddenly for unknown and unexpected reasons.

However, unlike Bloom, Keynes argued that although it is possible to measure risk where there exists a known probability distribution over a set of events, it was not possible to measure uncertainty.

"By uncertain knowledge, let me explain, I do not mean merely to distinguish what is known for certain from what is only probable. The game of roulette is not subject, in this sense, to uncertainty; nor is the prospect of a Victory bond being drawn. Or, again, the expectation of life is only slightly uncertain. Even the weather is only moderately uncertain. The sense in which I am using the term is that in which the prospect of a European war is uncertain, or the price of copper and the interest rate twenty years hence, or the obsolescence of a new invention, or the position of private wealth holders in the social system in 1970. About these matters there is no scientific basis on which to form any calculable probability whatever. We simply do not know.” (Keynes, QJE 1937, 213-214).

Further he argued that investment fluctuations were influenced by “animal spirits”.

"Even apart from the instability due to speculation, there is the instability due to the characteristic of human nature that a large proportion of our positive activities depend on spontaneous optimism rather than on a mathematical expectation, whether moral or hedonistic or economic. Most, probably, of our decisions to do something positive, the full consequences of which will be drawn out over many days to come, can only be taken as a result of animal spirits - of a spontaneous urge to action rather than inaction, and not as the outcome of a weighted average of quantitative benefits multiplied by quantitative probabilities. Enterprise only pretends to itself to be mainly actuated by the statements in its own prospectus, however candid and sincere. Only a little more than an expedition to the South Pole, is it based on an exact calculation of benefits to come. Thus if the animal spirits are dimmed and the spontaneous optimism falters, leaving us to depend on

\footnotetext{
5 See Davidson (1991), and a debate about Keynesian uncertainty between O’Donnell (2014) and Davidson 2015). Also see Dequech (2011) for an extended discussion of different varieties of "uncertainty".

6 See Nevile \& Kriesler (2008)
} 
nothing but a mathematical expectation, enterprise will fade and die; — though fears of loss may have a basis no more reasonable than hopes of profit had before.

It is safe to say that enterprise which depends on hopes stretching into the future benefits the community as a whole. But individual initiative will only be adequate when reasonable calculation is supplemented and supported by animal spirits, so that the thought of ultimate loss which often overtakes pioneers, as experience undoubtedly tells us and them, is put aside as a healthy man puts aside the expectation of death.” (Keynes, GT, pp.161-162, emphasis added)

Keynes distinguishes between "speculation" (forecasting psychology of market) and "enterprise” (forecasting prospective yields). Enterprise depends on “animal spirits”.

Because of uncertainty he assumes that economic actors will assume that the "existing state of affairs will continue indefinitely" (Keynes, 1936, p.152).

\section{Keynes comparing a stock market to a beauty contest:}

"It is not a case of choosing those [faces] that, to the best of one's judgment, are really the prettiest, nor even those that average opinion genuinely thinks the prettiest. We have reached the third degree where we devote our intelligences to anticipating what average opinion expects the average opinion to be. And there are some, I believe, who practice the fourth, fifth and higher degrees." (Keynes, General Theory of Employment, Interest and Money, 1936).

Hence, predicting the future behaviour of the stock market is not possible. ${ }^{7}$

Minsky (1993) had argued that the interlinkages between the financial and real structure of the economy would lead to instability.

\section{How do people form expectations about future events?}

In many aspects of economic life people have to think about the future: whether it is firms deciding on whether to invest in a new machine or for a consumer to decide on whether to buy a new durable commodity like (say) a car. Firms have to think about whether their future sales are likely to increase or not, while consumers have to think about whether they should wait in case prices are going to fall in the future, or buy now in case prices are going to rise in the future. How do people form expectations about the future? For most purposes people may form expectations about events that are based on the future being similar to the past.

For many years macroeconomists used a simple procedure to determine the future behaviour of (say) prices: simply extrapolate the past behaviour. For many occasions that is a simple and often reasonable procedure to forecast future movements. In formal econometric models parameter estimates would help to forecast (project) the future on the assumption that the structure of the model did not change (the parameter vector remained constant), that is, the economic behaviour of the agents in the economy did not change. In some more formal econometric modelling it was hypothesised that people formed their expectations adaptively, they adapted their previous estimates of expected (say) prices by the error in their estimates they had made in the previous period. This procedure was called "adaptive expectations".

\footnotetext{
${ }^{7}$ See Skidelsky (2011).
} 
However, it was then pointed out that this procedure would consistently underestimate (overestimate) the future paths if the variable in question was trending upwards (downwards).

As a result, Lucas (1972) put forward the concept of "Rational Expectations" (RE) in macroeconomic models, following Muth (1961). Under this hypothesis agents would use all the information available to forecast the future paths of economic variables and they would be correct on average. This implied that agents would have, in effect, a complete model of the economy which was the "true model". Much of macroeconomics then built models with RE embedded in them. This is not the place to provide critical exposition of this concept except to state that it is clearly not how people in fact behave as it would require all agents to have not only a huge amount of data but also access to large and efficient computing systems. The Global Crisis (Global Financial Crisis, GFC) clearly exposes the absurdity of this concept of RE.

Agents may formulate expectations not only about economic variables but also about the behaviour of institutions like the Government, Central Banks, Trade Unions, etc. Similarly, these institutions would formulate expectations about how agents would respond to their behaviour. This could lead to a problem of infinite regress and hence we may not get any sensible solutions.

Given there is uncertainty in the world, it is impossible to forecast the future with any degree of certainty. This is especially true when there is a sudden change in moods, for example the sudden collapse of financial institutions in the USA, which led to the collapse of the financial system in many other countries and led to the so-called Great Recession.

But how people form expectations about some future variable depends on their knowledge about the world and also about their psychology. Our view about the future of the world is also influenced by "crowd behaviour": our views are influenced by our family, friends and neighbours. Why should one waste time forming expectations about (say) inflation if we are not concerned about buying/selling in the near future? Clearly we do not form expectations about (say) the exchange rate if we are not planning any foreign trips or planning to purchase goods from overseas.

It is interesting that although "expectations" play an important role in economics, there has been little effort to find out how people form expectations by using survey methods or by using experimental methods. There are a few papers that use survey data, see Berc (1999). As Keynes argued, we may form expectations about certain events (or variables) like the inflation rate or the exchange rate, but it is impossible to form expectations about the likelihood of (say) a nuclear war.

\section{How do people treat risk and uncertainty: a symmetric distribution of risks or a skewed distribution of risks?}

Is "risk" necessarily bad for individuals, firms, or the economy? It is now common to measure "risk" by looking at the past behaviour of (say) stock prices and using the variance (or standard deviation) of the past few periods as an index of risk. Using a variance measure of risk based on several years of data, as for example by insurance companies, allows the firm to spread the risk over several agents. Even if the "average" measure does not reflect accurately the risk faced by any one individual, it averages out over several thousand or millions of insured agents (as long as these risks are independent) ${ }^{8}$. Two aspects are important: firstly, the data must be

8 See Roy (1952), p. 431 
collected over a very long period so that the variances are not likely to provide false information: if the data have been collected over a short period where (say) house prices had been rising continuously the data could not conceivably reflect what would happen in a downturn. If the asset that is being studied is a new asset with a short history, the time path of the price of this asset is not a good indication of its behaviour in the long run. Secondly, if it is not possible to "spread the risk" over a large number of agents where the risks are independent of each other, then this risk measure is problematic.

However, this procedure (a variance measure of risk) treats upwards and downwards movements in the stock prices as being equally bad (or risky). Most firms are happy if they sell more than they expected. They are unhappy if sales fall below expectations. Firms that sell (say) commodities in the international market prefer to see prices rising to prices falling. They are concerned about the downside risk, not the upside risk. Firms prefer to have input prices falling rather than rising. Consumers are concerned about prices rising, but would prefer prices falling. Workers prefer real wages rising to them falling. Preferences are asymmetric to upwards and downwards movements in some key variables.

There is a large literature in behavioural economics that shows that individuals are loss averse. ${ }^{9}$ Kahneman and Tversky $(1979,1984)$ show that behaviour in experimental settings contradict expected utility axioms. They put forward the Prospect Theory hypothesis where individuals initially "edit" the choices in a preliminary analysis and subsequently evaluate the choices. In particular, they emphasise that choices are made over differences not over the absolute amounts. In experimental economics literature it is now common to be concerned about the "framing" of the choices: the order in which choices are given influence the outcomes. The literature on loss aversion shows clearly that people treat losses differently from gains. See Thaler et al. (1997), Kahneman et al. (1991). These results have the clear implication that we cannot use a symmetric function (variance or standard deviation) to express risk: a loss of $\$ 100$ dollars hurts more than the gain of \$100 increases pleasure!

\footnotetext{
${ }^{9}$ An early discussion is in Roy (1952) where he argues that people may follow a safety first principle.
} 
Diagram 1: Path of Sales

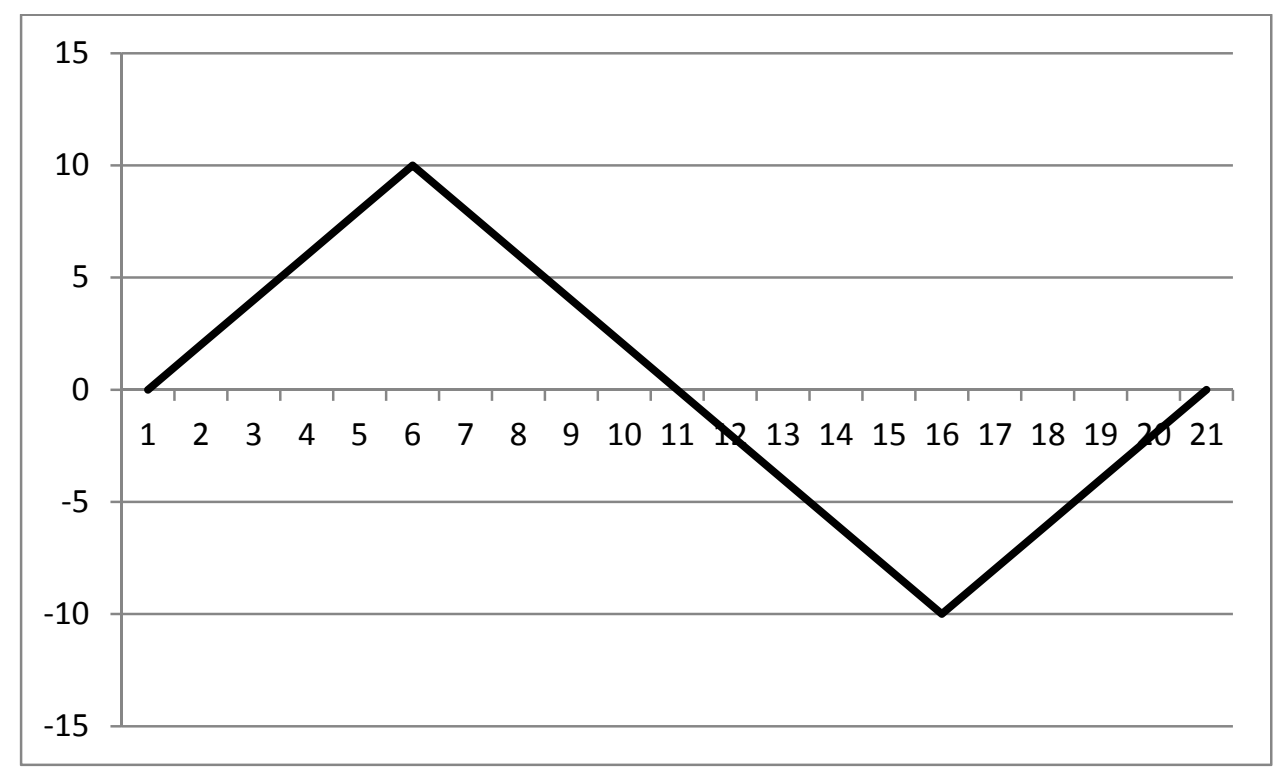

In Diagram 1 we draw the path of sales of an imaginary firm (where the values are deviations from a linear trend). As constructed, the path has a standard deviation of 3.6 for the first 11 periods and the same standard deviation for the periods from 11 to 21 . A firm faced with such a time path of sales would treat the first period as being good for investment and the second period bad for investment even though the standard deviations (or variances) are the same. Hence it is incorrect to use a symmetric measure to measure risk.

In financial markets where agents are interested in speculation for short term gains, often they are concerned about what other agents are thinking about the future path of stock prices. This creates "herding” behaviour, see Baddeley, Chapter 11 (2013). This kind of behaviour helps to create bubbles in financial markets.

If house prices are falling people postpone selling their properties: they are avoiding losses. If a consumer is buying a durable consumer good (e.g. cars, refrigerators, etc.) and they expect prices to fall they would postpone purchases. If firms are considering purchasing producer assets (investing in real capital goods) and they expect their sales to fall in the near future they would delay the purchase of the capital equipment. The firms treat investment under uncertainty like a financial market “option”, see inter alia, Abel (1983), Bernanke (1983), and McDonald and Siegel (1986). This approach was elegantly formalized and "codified" in Dixit and Pindyck (1994) that looks at investment under uncertainty. It treats investment as a financial option with irreversible investment: a firm can either invest now or wait to see how the future unravels. There is an opportunity cost of waiting, and there is an expected return from waiting. In everyday life consumers who are planning to buy a computer for their household may decide whether to buy it now or wait to see if the price of the computer is going to fall or whether it is going to be more powerful. There is an opportunity cost (loss of its use while waiting) but a potential benefit (a lower price or a more powerful computer). If I think I may lose my job, I would lower my consumption expenditures and cut back on non-essentials (e.g. restaurant meals, holidays, etc.). As a result household saving can increase as happened after the Global Recession (Great Recession). 


\section{An Alternative view of "uncertainty"}

In this section I discuss an alternative view of "uncertainty" as distinguished from "fundamental uncertainty". (Note I am denoting "uncertainty" in quotation marks from fundamental uncertainty in the Keynesian sense.) It is possible to think about "uncertainty" as leading to changes in the views of agents about the future probabilities of "good" or "bad" outcomes. This can be represented by a (Bayesian) subjective probability distribution of expected outcomes that is not given, but shifts with changes in optimism or pessimism, see Diagram 2 below. Unlike the idea of a known distribution of probabilities that underlies the concept of "risk", under "uncertainty" the expectations of the agents may shift due to changes in moods or views about the future. This is illustrated below in Diagram 2. Assuming this reflects the expectations of (say) sales, a firm with optimistic expectations (the continuous blue curve) would be happy to invest in new capital expenditures. But if the mood changes due to some unforeseen event, the subjective probability distribution may shift to the left (the broken red curve) and the firm would hold back investment expenditures.

\section{Diagram 2: Moods of Optimism and Pessimism}

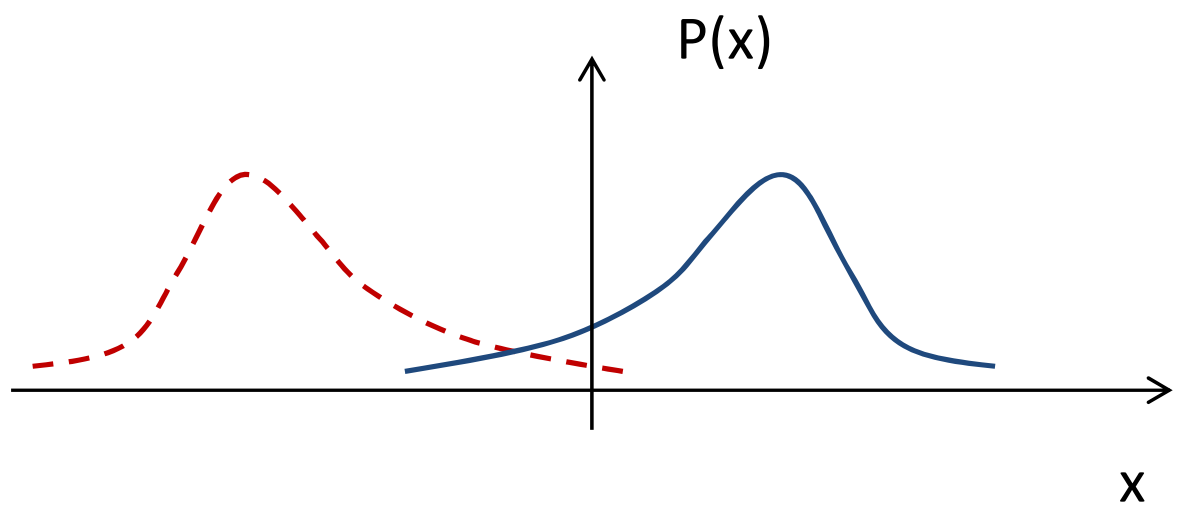

What leads to these shifts of mood? There are many factors that could lead to a change in the mood of firms: if they believe that there is going to be a war in the Middle East near the oil producing nations, they would suddenly believe that oil prices may rise. If they believe that environmental regulations are likely to be introduced, then firms that use fossil fuels may become pessimistic about their sales, but producers of green technology products (solar panels) would get optimistic about their sales. If there is a sudden change in the government in China, firms may get pessimistic about the future sales. However, I am not suggesting that the Bayesian probability distribution is changing in response to new information and "learning" is taking place. I am arguing that these subjective probability distributions are subject to sudden shifts for unknown reasons. The shift in expectations could simply be due to "animal spirits", as discussed by Keynes:

"Most, probably, of our decisions to do something positive, the full consequences of which will be drawn out over many days to come, can only be taken as the result of animal spirits - a spontaneous urge to action rather than inaction, and not as the outcome of a weighted average of quantitative benefits multiplied by quantitative probabilities."

(The General Theory of Employment Interest and Money, 161-162) 
Alchian (1950) in an interesting paper says:

"First, to clear the ground, a brief statement is given of a generally ignored aspect of "profit maximization," that is, where foresight is uncertain, "profit maximization" is meaningless as a guide to specifiable action.” (Alchian, 1950, p. 211)

"Adaptive, imitative, and trial-and-error behavior in the pursuit of "positive profits" is utilized rather than its sharp contrast, the pursuit of "maximized profits." (Alchian, 1950, p. 211)

"... those who realize positive profits are the survivors; those who suffer losses disappear.” (Alchian, 1950, p. 213)

In other words, when firms face "uncertainty", it is not possible to use simple models of maximising utility or expected utility to explain the behaviour of firms or consumers. As Shackle points out using the concept of expected utility requires a set of assumptions to hold:

"We can use mathematical expectations (actuarial decisions) under following conditions:

1. We are sure that the system, whose behaviour we wish to know, will remain a given system and not undergo changes during the interval of future time in question.

2. We are only interested in the total result of a 'large number' of trials, all of which count equally or virtually so in building up this total.

3. We feel sure that we shall, in fact, have the opportunity to carry out a sufficient number of trials ..."

(Shackle, 1949, p. 6)

To summarise this section: I have argued that although we do not have an objective distribution of probabilities facing firms or individuals (that is, they do not face risk) it is possible to characterise their expectations about the future in terms of a subjective probability distribution that shifts due to sudden and unexpected events. Given this subject probability distribution shifts for unknown reasons, it is impossible to measure risk. Hence, it is meaningless to use the concept of maximising expected utilities with a given probability distribution. 


\section{Some Concluding Comments}

In this paper I have argued that measuring risk by volatility indexes (variances or standard deviations) does not capture the way people respond to gains versus losses. In particular, agents do not treat gains and losses symmetrically: behavioural economics has shown us that individuals are loss averse. The paper also argued that as discussed by Keynes and others, fundamental uncertainty is not a measurable concept and is distinctly different from measurable risk. In the next section I argued that it is possible to represent "uncertainty" by Bayesian subjective probability distributions that shift with changing moods of optimism and pessimism. As these subjective probability distributions are likely to shift suddenly, we cannot study their impact on economic behaviour as these shifts are likely to be determined by "animal spirits". 


\section{Appendix}

\section{BOX 1A: DEFICIENCIES IN VAR BASED ESTIMATES OF RISK}

\section{Basic concept}

- Observe over a past period (e.g. last year) the distribution of profits / loss resulting over a defined time period (e.g. day, 10 days) from a given gross position.

- Hold capital sufficient to cover some multiple of this 'Value at Risk'.

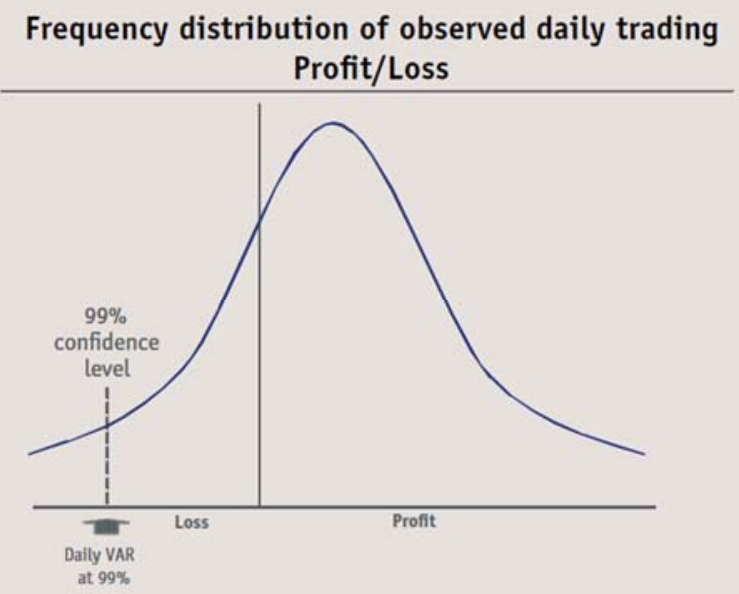

\section{Procyclicality}

Volatility in specific market (see exhibit 1.17 for real example)

Short-term observation periods (e.g. one year) can result in significant procyclicality.

- Observation 1 reflects low volatility and thus low apparent risk; capital is attracted to position taking, reinforcing market liquidity

- Observation 2 reflects high volatility following fall in confidence; liquidity dries up, exacerbating increase in volatility

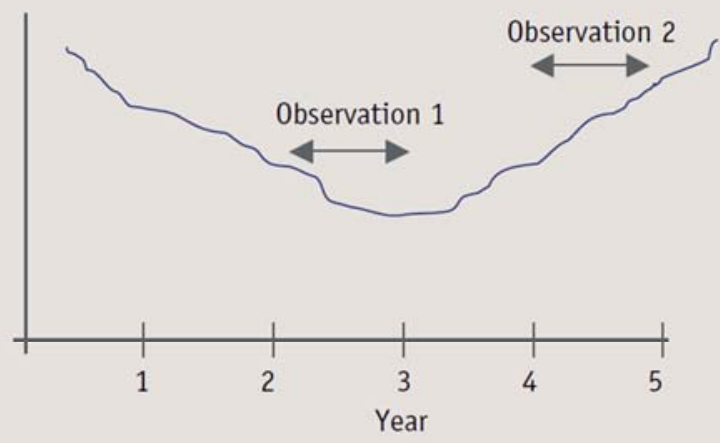

\section{Failure to capture fat-tail risks}

- Short-term observation periods plus assumption of normal distribution can lead to large underestimation of probability of extreme loss events.

\section{Failure to capture systemic risk}

- Methodology assumes each institution is individual agent whose actions do not themselves affect the market.

- Interconnected market events ('network externalities') can produce self-reinforcing cycles which models do not capture.

- Systemic risk may be highest when measured risk is lowest, since low measured risk encourages behaviour which creates increased systemic risks.

Source: Turner (2009), p. 23 


\section{References}

Abel, A.B. (1983), ‘Optimal Investment under Uncertainty’, American Economic Review, 73, March, pp. 228-33.

Alchian, A.A. (1950) “Uncertainty, Evolution and Economic Theory” Journal of Political Economy, 58, 211-221.

Baddeley, Michelle (2013) Behavioural Economics and Finance, Routledge, Oxford.

Baker, Scott R., Nicholas Bloom and Steven J. Davis (2015) "Measuring Economic Policy Uncertainty”, NBER Working Paper No. 21633.

Berk, Jan Marc (1999) “Measuring inflation expectations: a survey data approach”, Applied Economics, 31, 1467-1480.

Bernanke, B.S. (1983), 'Irreversibility, Uncertainty, and Cyclical Investment', Quarterly Journal of Economics, 98, February, pp. 85-106.

Bloom, Nicholas (2014) “Fluctuations in Uncertainty”, Journal of Economic Perspectives, 28 (2), 153-176.

Brenner, Menachem, and Galai, Dan. "Hedging Volatility in Foreign Currencies," The Journal of Derivatives, Fall, 1993.

Camerer, Colin and Weber Martin (1992) "Recent Developments in Modelling Preferences: Uncertainty and Ambiguity” Journal of Risk and Uncertainty, 325-70.

Davidson, Paul (1991) "Is Probability Theory Relevant for Uncertainty? A Post-Keynesian Perspective”, Journal of Economic Perspectives, 5 (1), 129-143.

Davidson, Paul (2015) “A rejoinder to O’Donnell’s critique of the ergodic/non-ergodic explanation of Keynes's concept of uncertainty”, Journal of Post Keynesian Economics, 38, 1-18.

Dequech, David (2011) “Uncertainty: A Typology and Refinements of Existing Concepts”, Journal of Economic Issues, 45, 621- 640.

Dixit, A.K. and R.S. Pindyck (1994), Investment under Uncertainty, Princeton: Princeton University Press.

Financial Services Authority (2009) The Turner Review: A regulatory response to the global banking crisis.

Kahneman, Daniel (2003) "Maps of Bounded Rationality: Psychology for Behavioral Economics”, American Economic Review, 93 (5), 1449-1475.

Kahneman, Daniel and Amos Tversky (1979) "Prospect Theory: An Analysis of Decision under Risk”, Econometrica, 47, 263-292.

Kahneman, Daniel and Amos Tversky (1984) “Choices, Values, and Frames”, American Psychologist, 39 (4), 341-350. 
Kahneman, Daniel, Jack L. Knetsch and Richard H. Thaler (1991) "The Endowment Effect, Loss Aversion, and Status Quo Bias” Journal of Economic Perspectives, 5 (1), 193-206.

Kelsey, David and Quiggin, John (1992) “Theories of Choice under Ignorance and Uncertainty”, Journal of Economic Surveys, 6 (2), 133-53.

Keynes, J.M. (1921, 1973) Treatise on Probability, The Collected Writings of John Maynard Keynes, Volume VIII, Published for the Royal Economic Society, Macmillan, London.

Keynes, J.M. (1936) The General Theory of Employment, Interest, and Money, London: Macmillan.

Keynes, J.M. (1937) “The General Theory of Employment”, Quarterly Journal of Economics, 209-223.

Knight, Frank H. (1921) Risk, Uncertainty, and Profit, Boston, MA: Houghton Mifflin Co.

Lucas, R.E. (1972), "Expectations and the Neutrality of Money," Journal of Economic Theory, 4, 103-124.

Minsky, Hyman P. (1993) “The Financial Instability Hypothesis”, Prepared for Handbook of Radical Political Economy, edited by Philip Arestis and Malcolm Sawyer, Edward Elgar, Aldershot.

Moore, Angus (2016) “Measuring Economic Uncertainty and Its Effects”, RBA Research Discussion Paper 2016-01.

Muth, J.F. (1961) "Rational Expectations and the Theory of Price Movements,"Econometrica, 29, 315-335.

Nevile, J.W. and Peter Kriesler (2008) “Expectations and Unemployment”, in Keynes and Macroeconomics after 70 Years: Critical Assessments of The General Theory Wray, R and Forstater, M. (eds.), Edward Elgar: Cheltenham, pp 355-359.

Newman, Peter (2008) "Ramsey, Frank Plumpton (1903-1930). The New Palgrave Dictionary of Economics. Second Edition. Eds. Steven N. Durlauf and Lawrence E. Blume. Palgrave Macmillan, 2008. The New Palgrave Dictionary of Economics Online. Palgrave Macmillan. 24 March 2016< http://www.dictionaryofeconomics.com/article?id=pde2008_R000011> doi:10.1057/9780230226203.1382

O’Donnell, Rod (2013) “Two Post-Keynesian Approached to Uncertainty and Irreducible Uncertainty”, Chapter 5, The Oxford Handbook of Post-Keynesian Economics, Volume 2, Oxford University Press, New York, NY.

O’Donnell, Rod (2014) “A critique of the ergodic/nonergodic approach to uncertainty”, Journal of Post Keynesian Economics, 37, 187-209.

Roy, A.D. (1952) “Safety First and the holding of Assets”, Econometrica, 20 (3), 431-449.

Savage, Leonard J. (1972) The Foundations of Statistics, Second Edition, Dover Publications, New York.

Shackle, G.L.S. (1949) Expectation in Economics, Cambridge University Press, Cambridge. 
Skidelsky, Robert (2011) “The Relevance of Keynes”, Cambridge Journal of Economics, 35, $1-13$.

Thaler, Richard H., Amos Tversky, Daniel Kahneman and Alan Schwartz (1997) “The Effect of Myopia and Loss Aversion on Risk Taking: An Experimental Test” Quarterly Journal of Economics 112 (2), 647-661.

United States of America Financial Crisis Inquiry Commission (2011) The Financial Crisis Inquiry Report, U.S. Government Printing Office, Washington DC. 